\title{
Nonlinear Dynamics in Economics \& Finance and Unit Root Testing
}

\author{
Efthymios G Pavlidis Ivan Paya David A Peel Costas Siriopoulos
}

\begin{abstract}
This paper illustrates the flexibility of the ESTAR model to encompass a number of different characteristics found in economic and financial series, such as multiple equilibria, complex dynamics, chaotic-like behavior, and spurious trends. We then re-assess the power of the Kapetanios et al. (2003), Enders and Granger (1998), and Augmented Dickey Fuller unit root tests in the presence of nuisance parameters for parameter values typically encountered in the empirical literature. Our results show the lack of dominance of any particular test and that the power is not independent to priors about the nuisance parameters. Finally, we examine several asset price deviations from fundamentals and one hyper-inflation series and find contradictory results between the nonlinear fitted models and unit root tests. The findings highlight that new testing procedures with higher power are desirable.
\end{abstract}

Keywords: Asset Prices, Fundamentals, Hyper-inflation, Nonlinear Dynamics, Multiple Equilibria, Persistence

JEL Classification: C12, C32 


\section{Introduction}

Traditional models in economics and finance establish a linear framework for analyzing prices, fundamentals as well as the relationship between them. Regarding stock markets, the cost of carry model predicts that stock futures prices should comove with spot prices (Taylor et al., 2000). Further, loglinear present value models imply a linear relationship between log dividends and prices (Campbell and Shiller, 1988). Similarly in the housing market, as long as that the real value of residential property is a constant proportion of the expected value of future real disposable income, the house price to income ratio should be stable (Black et al., 2006).

However, in most cases the results of empirical research based on linear unit root tests are discouraging. Deviations from fundamental values appear to wonder with no apparent tendency to revert to a single equilibrium point. This is in sharp contrast to the theory. During the last two decades numerous theoretical and empirical contributions have attempted to provide possible explanations for this empirical regularity. An important finding of these studies is that the failure to find economically meaningful results may be attributed to the assumption of linearity. Linear unit root tests may result in misleading inference in the presence of nonlinear dynamics regarding the mechanism characterizing the macroeconomy and asset markets.

A family of nonlinear models which is gaining popularity in finance and macroeconomics is the smooth transition autoregressive (STAR). The STAR functional form has three particularly appealing features. First, it is in line with the presence of limits to arbitrage in financial and commodity markets due to market frictions, uncertainty regarding equilibrium asset prices and heterogeneous agents which make deviations from equilibrium and arbitrage conditions inherently nonlinear and persistent. To this end, applications of the STAR process include modeling deviations from the covered interest parity (Peel and Taylor, 2002), spot-futures relationship (Sarno and Monoyios, 2002), dividend-price ratios (Gallagher and Taylor, 2001), deviations of nominal exchange rates

from the equilibrium value suggested by the Purchasing Power Parity (PPP) (Michael et al., 1997; 
Taylor et al., 2001; Kilian and Taylor, 2003), as well as optimal money holdings (Sarno et al., 2003).

Second, this particular type of nonlinear models can display multiple equilibria. This property might turn out to be crucial for capturing the salient aspects of series such as real interest rates and inflation. Models of monetary policy rules suggest that once you take into account the zero bound on nominal interest rates, real interest rates might follow a number of equilibria (see, e.g., Benhabib et al., 2001). Moreover, in their seminal paper Sargent and Wallace (1973) show that when authorities print money so as to finance a real budget deficit inflation is a nonlinear process with two equilibria, one stable and the other unstable..$^{1}$ Moreover, a stylized fact regarding inflation is the high persistence of the series. In numerous empirical and theoretical contributions inflation is assumed to be a linear integrated of order one, I(1), process. This assumption has severe economic and statistical implications. The nominal exchange rate, via PPP, should be an I(2) process, and nominal asset returns would exhibit unit root behavior, which is in sharp contrast with the empirical findings.

Third, STAR models can exhibit complex, possibly chaotic, dynamics. There are a number of theoretical models that suggest this behavior in economics and finance. Day (1982) modifies the neoclassical growth model and shows that growth cycles can exhibit an asymmetric saw-toothed pattern. Grandmont (1985) employs overlapping-generations models so as to illustrate how a deterministic equilibrium model can produce regular asymmetric cycles as well as chaotic dynamics. Brock (1988) and De Grauwe et al. (1993) construct heterogeneous agents models which can generate similar complex behavior, or even chaos, in asset prices. Moreover, De Grauwe and Grimaldi (2006) and Kaizoji (2004) show that the presence of heterogeneous agents can lead to the generation of speculative bubbles in asset prices and financial crises. Chapell (1997) shows how a discrete version of the Sargent and Wallace (1973) model of hyper-inflation can exhibit both complex and

\footnotetext{
${ }^{1}$ In the case that agents form adaptive expectations the lower equilibrium is stable but not the higher, ruling out steady states of high inflation. However, Evans et al. (1996) illustrate that two stable solutions can occur and, therefore, a stable high inflation state may arise with adaptive learning.
} 
chaotic dynamics. All these arguments motivate a nonlinear adjustment mechanism with possible multiple equilibria and complex dynamics such as the one provided by the smooth transition regression model. Some of the properties of STAR models are illustrated below, in Section 2.

Given the widespread application of ESTAR models to time series which are highly persistent it is useful to examine the properties of a unit root test which derives from this family, and compare it with more general unit root tests. Kapetanios et al. (2003) (KSS hereafter) propose a testing procedure so as to formally distinguish between nonlinear single equilibria globally stationary processes and unit root processes. On the basis of Monte Carlo simulation experiments the authors conclude that their procedure improves substantially upon existing tests. In particular, their nonlinear unit root test appears to have better power properties that the standard Augmented Dickey-Fuller test, ADF hereafter, and the statistic proposed by Enders and Granger (1998), EG hereafter.

In Section 3 of this paper we attempt to extend the analysis of KSS in three directions. First, we employ a different range of parameter values than the ones considered initially by Kapetanios et al.. The new range approximates the range of values typically reported in the empirical literature and corresponds to ESTAR processes which exhibit more closely unit root like behavior. Second, we examine the impact of uncertainty regarding the presence of deterministic components in the Data Generating Process (DGP) on the performance of the test. Clearly, researchers are often ignorant and in many cases have no priors about the true DGP so that they have to rely on hypothesis testing to determine the significance of deterministic components. ${ }^{2}$ Finally, we investigate further the impact of multiple equilibria on the performance of the nonlinear test. This exercise is interesting given that the test is based on the assumption of a single equilibrium point.

Section 4 examines the performance of the unit root tests on financial and macroeconomic time series that have been suggested to follow nonlinear processes as mentioned above.

\footnotetext{
${ }^{2}$ Given that ESTAR models can exhibit spurious constants and trends (see Paya and Peel, 2003), the examination of the impact of the specification procedure on the performance of nonlinear tests appears important.
} 


\section{Modeling Nonlinear Economic \& Financial Dynamics with the STAR model}

A typical Exponential STAR (ESTAR) model for a univariate time series $y_{t}$ is given by

$$
y_{t}=\beta y_{t-1}+\gamma y_{t-1}\left[1-\exp \left(-\theta y_{t-d}^{2}\right)\right]+\epsilon_{t}
$$

or, equivalently,

$$
\Delta y_{t}=\phi y_{t-1}+\gamma y_{t-1}\left[1-\exp \left(-\theta y_{t-d}^{2}\right)\right]+\epsilon_{t}
$$

where $\beta, \gamma$ and $\theta$ are constants, $\phi=\beta-1$ and $\epsilon_{t} \sim \operatorname{iid}\left(0, \sigma^{2}\right)$ is the disturbance term. 3 When $\gamma<0$ and $\phi+\gamma<0$ the process is globally mean reverting although close to the equilibrium it may exhibit unit root or even explosive behavior. As aforementioned, the fact that STAR models allow the speed of mean reversion of the process towards the equilibrium to be a function of the distance from the equilibrium is particularly appealing in modeling several macroeconomic and financial variables. It has been proved that the presence of transactions costs and other market frictions in arbitrage models imply this type of nonlinear adjustment mechanism.

However, for different parameter values the ESTAR model can display multiple equilibria, complex dynamics and chaotic-like behavior that can lead to misleading conclusion when unit root tests are employed. For instance, consider the following model

$$
y_{t}=1.1 y_{t-1} \exp \left(-8.059\left(y_{t-1}-0.175\right)^{2}\right)+\epsilon_{t}
$$

which is globally stationary. Figure 1 , which depicts $\Delta y_{t}$ against $y_{t-1}$, shows that the process has three equilibria which correspond to the cases where the curve intersects with the horizontal axis. The stable equilibria are given by 0 and 0.283 . To shed more light on the properties of

\footnotetext{
${ }^{3}$ The assumption can be relaxed to allow $\epsilon$ to be a martingale difference sequence.
} 
the process, we simulate (2) without noise and a starting value of 0.1 . The first 100 realizations of the series are presented in Figure 2. The process moves from the starting value to the high equilibrium with oscillations. This behavior could be mistakenly interpreted as either explosive or suggestive of a time trend in small samples. Figure 3 shows 100 observations of the same process with the noise switched on. It can be observed that the series exhibits high persistence which makes it difficult to distinguish from a process with an intercept and trend, a unit root or even an explosive process. ${ }^{4}$ Lundbergh and Teräsvirta (2002) conduct a similar simulation experiment using a stationary Logistic STAR model with realizations that fluctuate between two local means. Their overall conclusion is that standard unit root tests when applied to these series do not reject the unit root hypothesis.

Figures 1, 2 and 3

Macroeconomic and financial series may in fact exhibit this type of behavior. Byers and Peel (2000) motivated by the theoretical literature on inflation dynamics fit ESTAR models to the inflation series of high-inflation countries. They examine Brazil and Argentina in the second half of the twentieth century and Germany in interwar period. ${ }^{5}$ Their results support the presence of multiple equilibria. In particular, Brazil has a stable high inflation equilibrium, while for the remaining two countries the high inflation state is characterized by inflation cycles. This finding has potential consequences for asset markets, such as the FX and bond markets, through spillover effects. Exchange rates, interests rates and asset returns are linked with prices through e.g. the PPP hypothesis and the Fisher equation.

The ESTAR model is also capable of mimicking chaotic type behavior which can arise in asset prices through the interaction of chartists and fundamentalists in the market. Heterogeneous agents models have been derived for the FX market (De Grauwe et al., 1993), the stock market

\footnotetext{
${ }^{4}$ Note that the ADF test statistic for this particular cannot rejected the null of a unit root at the 5 per cent level.

${ }^{5}$ Model 2 corresponds to the estimates for the case of Brazil. Please note that the speed of adjustment coefficient in Equation (2) has be scaled by the variance of the series.
} 
(Huang and Day, 1993) and the housing market (Kouwenberg and Zwinkles, 2010). To illustrate this point, we slightly modify Equation (2) by changing the autoregressive parameter from 1.1 to 1.5. Figure 4 illustrates the path of the series in the case of no noise for 200 observations. In this case, the series exhibit cycles of 34 periods. Close inspection of the figure would show that the values of the series do not ever repeat. Figure 5 shows a scatter diagram of $y_{t}$ on $y_{t-34}$ for the whole 10,000 replications, which corroborates this fact. Clearly, the above could be falsely considered as evidence in favor of chaotic behavior. This example highlights the importance of accurate econometric estimation and inference when dealing with highly complex dynamics. Coefficients values within the 95 per cent confidence interval could in fact have radically different economic implications for the series under consideration.

Figures 4 and 5

We have so far demonstrated the flexibility of a simple ESTAR model to nest a number of alternative processes with high persistence, spurious trends, multiple equilibria and chaotic-like behavior suggested by different theoretical models in the financial and economic literature. Given the popularity of the ESTAR model, KSS focus on the issue of persistence and propose a test to discriminate between a linear unit root process and a globally stationary ESTAR. The next section extends the work of KSS in examining its performance in cases of extreme persistence, multiple equilibria and no priors regarding the Data Generating Process (DGP) deterministic components.

\section{Kapetanios et al. (2003) Test}

Consider Equation (1) and let $\phi=0$ and $d=1$, it follows that

$$
\Delta y_{t}=\gamma y_{t-1}\left[1-\exp \left(-\theta y_{t-1}^{2}\right)\right]+\epsilon_{t}
$$


and by following Luukkonen et al. (1988) and taking a first-order Taylor series approximation

$$
\Delta y_{t}=\delta y_{t-1}^{3}+u_{t} .
$$

Under the null hypothesis of a linear unit root model, $H_{0}: \delta=0$. Whilst, under the alternative $H_{1}: \delta<0$. The KSS test statistic is given by

$$
t_{N L}=\frac{\hat{\delta}}{\text { s.e. }(\hat{\delta})},
$$

and converges weakly to a functional of Brownian motions.

In the presence of serial correlation in the residuals Equation (4) is augmented with lags of the dependent variable. Moreover, if the data exhibit an intercept/trend, $y$ must be replaced by the demean/detrended series. KSS employs a two step procedure. In the first stage, the researcher, who has a prior regarding the deterministic component characterizing the DGP, runs an Ordinary Least Squares regression of the raw data on an intercept or an intercept and a trend and obtains the residuals (demeaned or detrended series). In turn, the nonlinear unit root test is applied on the estimated residuals. However, when there is uncertainty about the presence of the deterministic components the econometrician typically regresses the raw data on an intercept or an intercept and a trend, and the ones that are not significant are omitted. We examine the effect of using hypothesis testing to specify the deterministic components of the DGP on the KSS and the EG test in the next section. It is also noted, that the ADF test is not based on this procedure. The test is always run with the raw data and then specific critical values for different restrictions are tabulated to select the DGP. Next, we follow KSS and compare the power of the $t_{N L}$ statistic with that of the ADF and EG test. 


\subsection{Monte Carlo Simulation, New Parameter Values}

KSS evaluate the power of their test by employing a DGP with speed of adjustment parameter $\theta \in$ $\{0.01,0.05,0.1,1\}$. The findings of recent empirical research (Taylor et al., 2001; Kilian and Taylor, 2003; Paya et al., 2003) suggest that even lower values of $\theta$ are warranted, in particular, values around $\theta=0.001$ are also reported in empirical work. 6 We employ this value as well as the more extreme case of $\theta=0.0001$ which is closer to the linear unit root case. Regarding $\gamma$ and $\phi$, we set them equal to -1 and 0 , which are the values reported or imposed in most empirical research on PPP or other arbitrage conditions. The nominal significance level is set equal to 5 per cent for all the experiments implemented in this study and the number of replications equal to 10,000 .

Table 1 reports rejection rates of the unit root hypothesis corresponding to the KSS, EG and ADF statistics. Case 1, Case 2 and Case 3 correspond to DGPs with no constant, constant and constant and trend, respectively. The results for the KSS and EG tests presented in Panel A are based on the procedure advocated by KSS where there are priors regarding the nuisance parameters. Not surprisingly, for relative high values of $\theta, 0.01$, the power of the $t_{N L}$ statistic is always higher or similar to the power of the ADF and the EG. As the value of $\theta$ decreases the power of all three statistics falls and when $\theta$ reaches 0.001 the power is reduced up to five times. It is important that the reduction in power is generally more severe for the KSS than the ADF so that in some cases (and always for $\theta=0.0001$ ) the latter becomes superior to the former.

Table 1

We now turn to Panel B where there is no prior regarding the deterministic components. Before we discuss the results we note that a constant and a trend is often found significant when the DGP has none, which alters the rejection probabilities of the KSS and EG tests. 7 Starting with the no

\footnotetext{
${ }^{6}$ In order to make comparisons across models and studies the speed of adjustment parameter must be standardized. That is, it must be divided by the variance of $y_{t-d}$.

${ }^{7}$ For instance, in sample sizes of 100 and 200 around seventy and sixty five per cent of the times, respectively, an intercept or a trend are found significant.
} 
constant DGP, Case 1, and the KSS test, the broad conclusion that emerges is that specifying the deterministic components on the basis of hypothesis testing results in lower power compared to Panel A. This is not always true for the remaining cases and, in particular, for small samples and low values of $\theta$. On the contrary, the EG test exhibits now greater power, especially, in small samples. It is also worth mentioning that now the ADF test outperforms the $t_{N L}$ statistic except in Case 3 for $\theta=0.01$ and $T$ equal to 100 and 200.8

\subsection{Monte Carlo Simulation, Multiple Equilibria}

In the previous exercise the ESTAR Model (1) has only one real equilibrium value, $\bar{y}=0$. However, with $\phi=0.1$ and $\gamma \in\{-1.5,-1,-0.5\}$, which are values employed by KSS, there are three equilibria. Specifically, the values of the equilibria are given by

$$
\bar{y}=0, \quad \text { and } \quad \bar{y}= \pm \sqrt{\frac{-\ln \left(\frac{\phi+\gamma}{\gamma}\right)}{\theta}} .
$$

The smaller the $\theta$ the further apart are the inner and outer equilibrium values. Figure 1 depicts four processes of ten thousand random realizations from Model (1) with $\phi=0.1, \gamma=-1$ and $\theta \in\{0.1,0.01,0.001,0.0001\}$. We emphasize that the relationship between the parameter $\theta$ and the degree of persistence appears to be non monotonic in the samples considered. As $\theta$ decreases the equilibria move further apart and the degree of persistence increases since shocks make the process bounce between equilibria. However, when the equilibria are sufficiently far apart the process remains in the neighborhood of only one of the equilibria for very long periods until a shock of sufficient magnitude bounces it to the other stable equilibria. Hence, the process may appear to be less persistent. Therefore, the relationship between the degree of persistence and the value of $\theta$ is not monotonic which motivates the examination the impact of different values of $\theta$ on

\footnotetext{
${ }^{8}$ The results for the ADF test are the same in Panel A and B due to the fact that the deterministic components are always obtain within the test.
} 
the power properties of the tests.

Figure 6

The two Panels of Table 2, report the power of the unit root tests for $\phi=0.1, \gamma=-1$, and $\theta \in\{0.01,0.001,0.0001\}$. Starting with Panel A, which is based on the KSS methodology outlined above, and in the case of a constant and a constant and a trend (Cases 2 and 3), it is interesting that the power of all tests increases as $\theta$ decreases. This finding may be attributed to the fact that, in small samples, the series with lower $\theta$ hardly ever change their equilibrium value and the persistence in the neighborhood of an equilibrium point is lower for lower values of $\theta .9^{9}$ This is also the reason that the power corresponding to 1,000 observations is lower than the power for 350. Note also that for low values of $\theta$ the KSS test performs worst than the competing unit root tests. Turning to Case 1 , we observe that while the power of the ADF increases as $\theta$ decreases, the power of $t_{N L}$ and EG become virtually zero. 10

\section{Table 2}

Panel B of Table 2 reports results for the same parameter values as above but with the specification of the deterministic components in the KSS and EG test being determined by hypothesis testing. Two results for the KSS test are worth mentioning. First, the test never displays the highest power except for Case 3 and $\theta=0.01$. Second, its power drops with respect to Panel A for $\theta=0.01$ but improves in the remaining cases.

\footnotetext{
${ }^{9}$ Please note that in Figure 1 the series with $\theta=0.001$ is more persistent (the autocorrelation coefficient is $\rho_{1}=$ $0.993)$ than the series with $\theta=0.01\left(\rho_{1}=0.945\right)$ for a sample of 10,000 observations. However, the persistence displayed by the series with $\theta=0.001$ is actually lower for small sample sizes similar to the ones used in our Monte Carlo $(T=100,200,350,1000)$. This is due to the fact that, in small samples, the series with lower $\theta$ hardly ever changes its equilibrium value and the persistence 'within' a regime (with $\rho_{1}$ around 0.84 ) is lower than in the case of $\theta=0.01\left(\rho_{1}=0.945\right)$.

${ }^{10}$ The power of the EG test is not reported for $\theta$ equal to 0.001 and 0.0001 due to the fact that the generated series take only positive (values) values making the computation of the statistic unfeasible.
} 
The overall conclusion of the above results is that the performance of the KSS test is not universally better than the EG and the ADF test but depends crucially on the DGP under examination and the methodology adopted for specifying the deterministic components of the data. The next section deals with the applications of the three unit root tests on real-world series.

\section{Empirical Applications}

In the introduction we highlighted the fact that numerous theoretical and empirical contributions suggest that factors such as agent heterogeneity, transactions costs, uncertainty regarding equilibrium values, or the sunk costs of international arbitrage can induce smooth transition nonlinearity in the deviation process of asset prices from their fundamental value in different asset markets (Dumas, 1992; Berka, 2005; Kilian and Taylor, 2001; Gallagher and Taylor, 2001; Kim and Bhattacharya, 2009). Many studies have further shown that these processes can be parsimoniously modelled by the ESTAR (Michael et al., 1997; Taylor et al., 2001; Kilian and Taylor, 2003; Sarno and Monoyios, 2002).

However, smooth transition nonlinearity is not constrained to deviations of asset prices from fundamentals. Sargent and Wallace (1973) show that when authorities print money so as to finance a real budget deficit inflation becomes a nonlinear process with multiple equilibria. Evans et al. (1996) illustrate further that under adaptive learning a stable high inflation state may arise. To this end, Byers and Peel (2000) advocate the use of ESTAR models which allow high persistence of the series as well as multiple equilibria.

Given all this evidence it seems interesting to test the properties of a number of series representative of those markets. Our data set consists of five real exchange rates, a house price-income ratio, a dividend-price ratio, a stock index basis, and an inflation series. The first real exchange rate series is the annual dollar-sterling $\left(q_{\mathrm{uk}, \mathrm{a}}\right)$ analyzed in Lothian and Taylor (1996). The series is extended by using data for the U.S. and U.K. consumer price indices and the dollar-sterling 
nominal exchange rate obtained from the International Financial Statistics (IFS) database. The extended data set covers the period from 1791 to 2005. The remaining four are monthly rates for the U.S.-U.K. $\left(q_{\mathrm{uk}}\right)$, U.S.-Japan $\left(q_{\mathrm{jp}}\right)$, U.S.-Canada $\left(q_{\mathrm{can}}\right)$ and U.S.-France $\left(q_{\mathrm{fr}}\right)$ country pairs, that cover the period January 1973 to December 2005. The series were constructed by using consumer price indices and nominal exchange rates from the IFS database. We employ the daily spot and futures prices of the FTSE 100 for the period January $1^{\text {st }} 1988$ to December $31^{\text {st }} 1998$ to construct the $\log$ FTSE 100 basis $\left(b_{\mathrm{ftse}}\right)$ as analysed in Sarno and Monoyios (2002). The next two series are the quarterly U.K. log house price-income ratio $(h p-y)$ and the monthly Nasdaq log dividend-price ratio $(d-p)$. Data for the former variable span the period 1983 to 2008 and are obtained from Nationwide and the IFS. Price and dividend data cover the period 1973 to 2008 and were downloaded from Datastream. The final series is the monthly inflation rate for Brazil $(\pi)$, which covers the period January 1957 to December 1990. The series is analyzed in Byers and Peel (2000) and Baillie et al. (1996) and can be downloaded from http://qed.econ.queensu.ca/jae/. In order to assess the significance of nonlinearities in all series but inflation we first fit nonlinear ESTAR models of the form proposed by Kilian and Taylor (2003):

$$
y_{t}=\xi_{0}+\sum_{i=1}^{p} \xi_{i}\left(y_{t-i}-\xi_{0}\right) \exp \left(-\frac{\theta}{\operatorname{var}\left(y_{t-1}\right)}\left(y_{t-1}-\xi_{0}\right)^{2}\right)+\eta_{t}
$$

where $\xi_{i}$ with $i=1, \ldots, p$ are parameters, $p$ denotes the lag order, and $\sum_{i=1}^{p} \xi=1.11$ The above parameterization is very appealing for modeling deviations from parity and equilibrium conditions. Unlike in a linear model, the process moves between a white noise and a unit root depending on the size of the deviation, $\left|y_{t-1}-\xi_{0}\right|$ and the speed of adjustment $\theta$. Intuitively, small deviations that do not cover transactions costs or the sunk costs of international arbitrage are left uncorrected and the process exhibits unit root behavior. On the other hand, large deviations are much less persistent. Given the size of the deviation, the speed of mean reversion increases with $\theta$. As far as

\footnotetext{
${ }^{11}$ The lag order $p$ is determined on the basis of the Akaike Information Criterion.
} 
the inflation for Brazil is concerned, we employ the estimates provided by Byers and Peel (2000). 12 These estimates indicate that the process moves between multiple equilibria, one of which is high and one low inflation.

Table 3

The second column of Table 3 shows the estimated $\theta$ coefficients. The estimates vary considerably across applications. Moreover, all coefficients are statistically significant at least at the 10 per cent significance level implying that the series are nonlinear and globally stationary. The maximum $\theta$ estimate is about 0.058 and corresponds to the annual dollar-sterling real exchange rate data. While, the minimum is about 0.004 , which lies outside the range examined by KSS but included in the previous section, for the real exchange rate of Canada.

These results have the following economic implications. Regarding real exchange rates, they suggest that prices and exchange rates are related with the adjustment mechanism being nonlinear. Moreover, they are in line with other studies which utilize nonlinear models and explain the documented difficulty of unit root tests typically employed in the 1980 s to reject the null hypothesis (Michael et al., 1997). Turning to the dividend-price ratio, the fact that $\theta$ is significant for the Nasdaq index complements the analysis of Gallagher and Taylor (2001) and rules out the presence of bubbles (the dot-com bubble) suggested by other studies. A similar conclusion can be drawn from the estimate of the speed of adjustment for the house price-income ratio of the U.K. housing market. The fact that the FTSE futures basis is nonlinearly mean reverting is in accordance with Sarno and Monoyios (2002) and stresses the importance of modeling stock market frictions.

Turning to the results displayed in the remaining columns of Table 3, we observe that the unit root hypothesis cannot be rejected for all the monthly real exchange rates, the house priceincome ratio and the dividend-price ratio. 13 On the other hand, the null is rejected for the annual

\footnotetext{
${ }^{12}$ Note that the authors adopt a slightly different ESTAR parameterization that the one of Kilian and Taylor (2003) allowing for the sum of the autoregressive coefficients to be different from unity.

${ }^{13}$ There are two exceptions, $q_{\mathrm{uk}}$ in the KSS constant case and $d-p$ in the KSS constant and trend case.
} 
dollar-sterling real exchange rate and the FTSE 100 basis for the constant and constant and trend cases. These two series have the highest estimated $\theta$ values. The fact that the number of rejections is substantially lower than the number of statistically significant $\theta$ coefficients raises concerns regarding the power of the tests which is consistent with the results of the previous section.

A particularly interesting case is the inflation rate series presented in the last row of the table. As mentioned above, Byers and Peel (2000) show that this process exhibits multiple equilibria, one with low inflation rate and one with high. The country appears to be in its low steady state until the mid-1980s (mean monthly inflation before 1986 was 3.6 per cent) and then to move slowly into the high state (the mean inflation for the period 1986 to 1990 was 17.3). The change from one equilibrium to the other has clearly severe consequences for unit root tests. The ADF which cannot account for multiple equilibria suggests that the series is explosive for the no constant and constant cases ${ }^{14}$ This has important economic implications since, via PPP, the Brazilian nominal exchange rate should also be explosive. Moreover, asset returns should exhibit a similar behavior. The results for the $t_{N L}$ and EG statistics, although do not imply an explosive behavior, still indicate that non stationarity cannot be rejected.

Overall, rejections of the null hypothesis for all tests appear to be related with the magnitude of the $\theta$ coefficient, the sample size and the existence of multiple equilibria. These results seem to be in line with the simulation experiments.

\section{Conclusions}

Over the last decades there has been a steadily increasing interest in the development and application of nonlinear time series models. In this study we focus on the widely used family of smooth transition autoregressive models, which appear to parsimoniously capture the nonlinear dependence of many economic and financial time series. Specifically, we illustrate the flexibility of the

\footnotetext{
${ }^{14}$ The critical values for the explosive alternative can be found in Fuller (1996).
} 
ESTAR model to encompass a number of different characteristics found in empirical work and suggested by the theoretical literature using market frictions and heterogeneous agents. These are multiple equilibria, complex dynamics, chaotic-like behavior, and spurious trends.

In turn, we examine the properties of a recently proposed unit root test against smooth transition stationary processes when there are no priors regarding the deterministic components and possible multiple equilibria. We also make comparison with two alternative unit root tests widely employed in the literature. Our results stress that the power of the tests is highly dependent on the properties of the series. Moreover, no test dominates the others.

Finally, we run several applications on the foreign exchange, stock and housing markets as well as a hyper-inflation series. Despite the fact that we can successfully fit nonlinear models implying a stable nonlinear adjustment mechanism which supports arbitrage conditions as well as globally stationary multiple equilibria inflation series, unit root tests fail, in general, to detect the mean reversion.

Overall, our findings suggest that the difficulty to reject the unit root property in many financial and macroeconomic data on the basis of unit root testing should not be regarded as conclusive evidence. In particular, the factors examined here can severely contaminate the power of both linear and nonlinear unit root tests. 


\section{References}

Baillie, Richard T., Ching-Fan Chung, and Margie A. Tieslau, "Analysing Inflation by the Fractionally Integrated ARFIMA-GARCH Model,” Journal of Applied Econometrics, 1996, 11 (1), 23-40.

Benhabib, Jess, Stephanie Schmitt-Grohe, and Martin Uribe, "Monetary Policy and Multiple Equilibria," American Economic Review, 2001, 91 (1), 167-186.

Berka, Martin, “General Equilibrium Model of Arbitrage Trade and Real Exchange Rate Persistence,” MPRA Paper 234, University Library of Munich, Germany 2005.

Black, Angela, Patricia Fraser, and Martin Hoesli, "House Prices, Fundamentals and Bubbles," Journal of Business Finance \& Accounting, 2006, 33 (9-10), 1535-1555.

Brock, W.A., "Nonlinearity And Complex Dynamics In Economics And Finance," Working papers, Wisconsin Madison - Social Systems 1988.

Byers, David J. and David A. Peel, "Non-linear Dynamics of Inflation in High Inflation Economies," Manchester School, 2000, 68 (0), 23-37.

Campbell, John Y. and Robert J. Shiller, “The Dividend-Price Ratio and Expectations of Future Dividends and Discount Factors," Review of Financial Studies, 1988, 1 (3), 195-228.

Chapell, D., "Chaotic behaviour in a simple model of inflation," Chaotic behaviour in a simple model of inflation, 1997, LXV, 235-243.

Day, R.H., "Irregular growth cycles," American Economic Review, 1982, 72 (3), 406-414.

De Grauwe, Paul and Mariana Grimaldi, "Exchange Rate Puzzles: A tale of Switching Attractors," European Economic Review, 2006, 50, 1-33. 
_, H. Dewachter, and M. Embrechts, Exchange Rate Theory: Chaotic Models of Foreign Exchange Markets, Oxford: Blackwell, 1993.

Dumas, Bernard, "Dynamic Equilibrium and the Real Exchange Rate in a Spatially Separated World," Review of Financial Studies, 1992, 5 (2), 153-80.

Enders, Walter and Clive W. J. Granger, "Unit-Root Tests and Asymmetric Adjustment with an Example Using the Term Structure of Interest Rates," Journal of Business \& Economic Statistics, 1998, 16 (3), 304-311.

Evans, George W., Seppo Honkapohja, and Ramon Marimon, "Convergence in Monetary Inflation Models with Heterogeneous Learning Rules," CEPR Discussion Papers, C.E.P.R. Discussion Papers January 1996.

Fuller, Introduction to Statistical Time Series, New York: Wiley, 1996.

Gallagher, Liam A. and Mark P. Taylor, "Risky Arbitrage, Limits of Arbitrage, and Nonlinear Adjustment in the Dividend-Price Ratio," Economic Inquiry, 2001, 39 (4), 524-36.

Grandmont, J.M., “On endogenous competitive cycles," Econometrica, 1985, 53 (4), 995-1045.

Huang, W. and R. Day, "Chaotically switching Bear and Bull Markets, The Derivation of Stock Price Distributions from Behavioral Rules," in R. Daya and P. Chen, eds., Nonlinear Dynamics and Evolutionary Economics, Oxford: Oxford University Press, 1993, pp. 169-182.

Kaizoji, Taisei, "Intermittent chaos in a model of financial markets with heterogeneous agents," Chaos, Solitons and Fractals, 2004, 20,323-327.

Kapetanios, George, Yongcheol Shin, and Andy Snell, "Testing for a Unit Root in the Nonlinear STAR Framework," Journal of Econometrics, 2003, 112 (2), 359-379. 
Kilian, Lutz and Mark P. Taylor, "Why is it so difficult to beat the random walk forecast of exchange rates,” Working Paper Series, European Central Bank November 2001.

_ and _ , "Why Is It So Difficult to Beat the Random Walk Forecast of Exchange Rates?,” Journal of International Economics, 2003, 60 (1), 85-107.

Kim, Sei-Wan and Radha Bhattacharya, "Regional Housing Prices in the USA: An Empirical Investigation of Nonlinearity," The Journal of Real Estate Finance and Economics, 2009, 38 (4), $443-460$.

Kouwenberg, Roy R. and Remco C. Zwinkles, "Chartists and Fundamentalists in the U.S. Housing Market,” Working Paper Series, SSRN 2010.

Lothian, James R. and Mark P. Taylor, "Real Exchange Rate Behavior: The Recent Float from the Perspective of the Past Two Centuries," Journal of Political Economy, 1996, 104 (3), 488509.

Lundbergh, S and Timo Teräsvirta, "Forecasting with Smooth Transition Autoregressive Models," in Michael P Clements and David F. Hendry, eds., A Companion to Economic Forecasting, Oxford: Blackwell, 2002.

Luukkonen, Ritva, Pentti Saikkonen, and Timo Tërasvirta, "Testing Linearity Against Smooth Transition Autoregressive Models," International Economic Review, 1988, 75 (3), 419-499.

Michael, Panos, Robert A. Nobay, and David A. Peel, “Transactions Costs and Nonlinear Adjustment in Real Exchange Rates: An Empirical Investigation," Journal of Political Economy, 1997, 105 (4), 862-79.

Paya, Ivan and David A. Peel, "Purchasing Power Parity Adjustment Speeds in High Frequency Data when the Equilibrium Real Exchange Rate is Proxied by a Deterministic Trend," Manchester School, 2003, 71 (Supplement 1), 39-53. 
_, Ioannis A. Venetis, and David A. Peel, "Further Evidence on PPP Adjustment Speeds: the Case of Effective Real Exchange Rates and the EMS," Oxford Bulletin of Economics and Statistics, 2003, 65 (4), 421-437.

Peel, David A and Mark P Taylor, "Covered Interest Rate Arbitrage in the Interwar Period and the Keynes-Einzig Conjecture," Journal of Money, Credit and Banking, 2002, 34 (1), 51-75.

Sargent, Thomas J. and Neil Wallace, "Rational Expectations and the Dynamics of Hyperinflation,” International Economic Review, 1973, 14 (2), 328-50.

Sarno, Lucio and Monoyios, "Mean reversion in stock index futures markets: A nonlinear analysis," Journal of Futures Markets, 2002, 22 (4), 285-314.

_, Mark P. Taylor, and David A. Peel, "Nonlinear Equilibrium Correction in U.S. Real Money Balances, 1869-1997," Journal of Money, Credit and Banking, 2003, 35 (5), 787-99.

Taylor, Mark P., David A. Peel, and Lucio Sarno, "Nonlinear Mean-Reversion in Real Exchange Rates: Toward a Solution to the Purchasing Power Parity Puzzles," International Economic Review, 2001, 42 (4), 1015-1042.

Taylor, Nick, Dick van Dijk, Philip Hans Franses, and Andre Lucas, "SETS, arbitrage activity, and stock price dynamics," Journal of Banking \& Finance, 2000, 24 (8), 1289-1306. 
Table 1: Power of Alternative Unit Root Tests

\begin{tabular}{|c|c|c|c|c|c|c|c|c|c|}
\hline \multicolumn{10}{|c|}{ Panel A } \\
\hline & \multicolumn{3}{|c|}{$\theta=0.01$} & \multicolumn{3}{|c|}{$\theta=0.001$} & \multicolumn{3}{|c|}{$\theta=0.0001$} \\
\hline Case 1 & $t_{N L}$ & EG & $\mathrm{ADF}$ & $t_{N L}$ & $\mathrm{EG}$ & ADF & $t_{N L}$ & EG & $\mathrm{ADF}$ \\
\hline$T=100$ & 0.917 & 0.259 & 0.866 & 0.178 & NA & 0.228 & 0.063 & NA & 0.135 \\
\hline$T=200$ & 0.997 & 0.958 & 0.998 & 0.612 & 0.147 & 0.478 & 0.094 & 0.059 & 0.169 \\
\hline$T=350$ & 1.000 & 0.998 & 1.000 & 0.972 & 0.351 & 0.861 & 0.203 & 0.071 & 0.232 \\
\hline$T=1000$ & 1.000 & 1.000 & 1.000 & 1.000 & 0.999 & 1.000 & 0.951 & 0.245 & 0.829 \\
\hline \multicolumn{10}{|l|}{ Case 2} \\
\hline$T=100$ & 0.477 & 0.245 & 0.481 & 0.100 & 0.100 & 0.252 & 0.052 & 0.061 & 0.141 \\
\hline$T=200$ & 0.954 & 0.908 & 0.960 & 0.195 & 0.146 & 0.412 & 0.074 & 0.070 & 0.168 \\
\hline$T=350$ & 1.000 & 0.996 & 1.000 & 0.498 & 0.303 & 0.726 & 0.106 & 0.081 & 0.228 \\
\hline$T=1000$ & 1.000 & 1.000 & 1.000 & 0.997 & 0.997 & 1.000 & 0.393 & 0.261 & 0.769 \\
\hline \multicolumn{10}{|l|}{ Case 3} \\
\hline$T=100$ & 0.267 & 0.164 & 0.252 & 0.089 & 0.081 & 0.113 & 0.055 & 0.052 & 0.078 \\
\hline$T=200$ & 0.814 & 0.686 & 0.761 & 0.115 & 0.115 & 0.161 & 0.060 & 0.058 & 0.091 \\
\hline$T=350$ & 0.988 & 0.967 & 0.991 & 0.280 & 0.216 & 0.251 & 0.083 & 0.079 & 0.117 \\
\hline$T=1000$ & 1.000 & 1.000 & 1.000 & 0.970 & 0.994 & 0.993 & 0.202 & 0.183 & 0.181 \\
\hline \multicolumn{10}{|c|}{ Panel B } \\
\hline & \multicolumn{3}{|c|}{$\theta=0.01$} & \multicolumn{3}{|c|}{$\theta=0.001$} & \multicolumn{3}{|c|}{$\theta=0.0001$} \\
\hline Case 1 & $t_{N L}$ & EG & $\mathrm{ADF}$ & $t_{N L}$ & $\mathrm{EG}$ & $\mathrm{ADF}$ & $t_{N L}$ & $\mathrm{EG}$ & $\mathrm{ADF}$ \\
\hline$T=100$ & 0.534 & 0.383 & 0.866 & 0.122 & 0.129 & 0.228 & 0.071 & 0.082 & 0.135 \\
\hline$T=200$ & 0.859 & 0.885 & 0.998 & 0.242 & 0.174 & 0.478 & 0.094 & 0.087 & 0.169 \\
\hline$T=350$ & 0.993 & 0.995 & 1.000 & 0.440 & 0.341 & 0.861 & 0.127 & 0.107 & 0.232 \\
\hline$T=1000$ & 1.000 & 1.000 & 1.000 & 0.982 & 0.997 & 1.000 & 0.298 & 0.228 & 0.829 \\
\hline \multicolumn{10}{|l|}{ Case 2} \\
\hline$T=100$ & 0.415 & 0.368 & 0.481 & 0.130 & 0.135 & 0.252 & 0.086 & 0.093 & 0.141 \\
\hline$T=200$ & 0.864 & 0.895 & 0.960 & 0.199 & 0.189 & 0.412 & 0.093 & 0.096 & 0.168 \\
\hline$T=350$ & 0.996 & 0.997 & 1.000 & 0.411 & 0.322 & 0.726 & 0.124 & 0.101 & 0.228 \\
\hline$T=1000$ & 1.000 & 1.000 & 1.000 & 0.982 & 0.995 & 1.000 & 0.297 & 0.240 & 0.769 \\
\hline \multicolumn{10}{|l|}{ Case 3} \\
\hline$T=100$ & 0.352 & 0.332 & 0.252 & 0.114 & 0.105 & 0.113 & 0.070 & 0.072 & 0.078 \\
\hline$T=200$ & 0.780 & 0.745 & 0.761 & 0.151 & 0.145 & 0.161 & 0.075 & 0.078 & 0.091 \\
\hline$T=350$ & 0.982 & 0.987 & 0.991 & 0.296 & 0.231 & 0.251 & 0.095 & 0.097 & 0.117 \\
\hline$T=1000$ & 1.000 & 1.000 & 1.000 & 0.970 & 0.994 & 0.993 & 0.202 & 0.183 & 0.181 \\
\hline
\end{tabular}


Table 2: Power of Alternative Unit Root Tests

\begin{tabular}{|c|c|c|c|c|c|c|c|c|c|}
\hline \multicolumn{10}{|c|}{ Panel A } \\
\hline & \multicolumn{3}{|c|}{$\theta=0.01$} & \multicolumn{3}{|c|}{$\theta=0.001$} & \multicolumn{3}{|c|}{$\theta=0.0001$} \\
\hline Case 1 & $t_{N L}$ & EG & $\mathrm{ADF}$ & $t_{N L}$ & $\mathrm{EG}$ & $\mathrm{ADF}$ & $t_{N L}$ & $\mathrm{EG}$ & $\mathrm{ADF}$ \\
\hline$T=100$ & 0.888 & 0.038 & 0.357 & 0.004 & NA & 0.628 & 0.000 & NA & 0.751 \\
\hline$T=200$ & 0.986 & 0.201 & 0.904 & 0.035 & NA & 0.915 & 0.000 & NA & 0.987 \\
\hline$T=350$ & 1.000 & 0.841 & 0.989 & 0.438 & NA & 0.948 & 0.000 & NA & 1.000 \\
\hline$T=1000$ & 1.000 & 1.000 & 1.000 & 0.784 & NA & 0.900 & 0.000 & NA & 1.000 \\
\hline \multicolumn{10}{|l|}{ Case 2} \\
\hline$T=100$ & 0.306 & 0.201 & 0.360 & 0.422 & 0.621 & 0.619 & 0.510 & 0.759 & 0.764 \\
\hline$T=200$ & 0.734 & 0.353 & 0.580 & 0.662 & 0.928 & 0.907 & 0.818 & 0.986 & 0.991 \\
\hline$T=350$ & 0.925 & 0.833 & 0.952 & 0.743 & 0.968 & 0.962 & 0.910 & 0.999 & 0.999 \\
\hline$T=1000$ & 0.999 & 1.000 & 1.000 & 0.650 & 0.926 & 0.904 & 0.962 & 1.000 & 1.000 \\
\hline \multicolumn{10}{|l|}{ Case 3} \\
\hline$T=100$ & 0.211 & 0.144 & 0.260 & 0.271 & 0.463 & 0.510 & 0.325 & 0.623 & 0.752 \\
\hline$T=200$ & 0.489 & 0.299 & 0.326 & 0.549 & 0.886 & 0.835 & 0.705 & 0.970 & 0.964 \\
\hline$T=350$ & 0.821 & 0.641 & 0.489 & 0.663 & 0.952 & 0.940 & 0.847 & 0.994 & 0.995 \\
\hline$T=1000$ & 1.000 & 0.991 & 0.994 & 0.629 & 0.907 & 0.909 & 0.934 & 1.000 & 1.000 \\
\hline \multicolumn{10}{|c|}{ Panel B } \\
\hline & \multicolumn{3}{|c|}{$\theta=0.01$} & \multicolumn{3}{|c|}{$\theta=0.001$} & \multicolumn{3}{|c|}{$\theta=0.0001$} \\
\hline Case 1 & $t_{N L}$ & EG & $\mathrm{ADF}$ & $t_{N L}$ & $\mathrm{EG}$ & $\mathrm{ADF}$ & $t_{N L}$ & EG & $\mathrm{ADF}$ \\
\hline$T=100$ & 0.326 & 0.261 & 0.357 & 0.389 & 0.628 & 0.628 & 0.465 & 0.750 & 0.751 \\
\hline$T=200$ & 0.593 & 0.443 & 0.904 & 0.665 & 0.919 & 0.915 & 0.797 & 0.979 & 0.987 \\
\hline$T=350$ & 0.871 & 0.833 & 0.989 & 0.715 & 0.949 & 0.948 & 0.908 & 0.998 & 1.000 \\
\hline$T=1000$ & 1.000 & 0.996 & 1.000 & 0.673 & 0.906 & 0.900 & 0.964 & 1.000 & 1.000 \\
\hline \multicolumn{10}{|l|}{ Case 2} \\
\hline$T=100$ & 0.312 & 0.301 & 0.360 & 0.405 & 0.618 & 0.619 & 0.491 & 0.755 & 0.764 \\
\hline$T=200$ & 0.570 & 0.412 & 0.580 & 0.650 & 0.910 & 0.907 & 0.793 & 0.987 & 0.991 \\
\hline$T=350$ & 0.895 & 0.770 & 0.952 & 0.742 & 0.964 & 0.962 & 0.899 & 0.999 & 0.999 \\
\hline $\begin{array}{c}T=1000 \\
\text { Case } 3\end{array}$ & 1.000 & 0.993 & 1.000 & 0.65 & 0.903 & 0.904 & 0.957 & 1.000 & 1.000 \\
\hline$T=100$ & 0.229 & 0.220 & 0.260 & 0.317 & 0.536 & 0.510 & 0.387 & 0.657 & 0.752 \\
\hline$T=200$ & 0.508 & 0.368 & 0.326 & 0.554 & 0.887 & 0.835 & 0.706 & 0.970 & 0.964 \\
\hline$T=350$ & 0.821 & 0.641 & 0.489 & 0.663 & 0.952 & 0.940 & 0.847 & 0.994 & 0.995 \\
\hline$T=1000$ & 1.000 & 0.991 & 0.994 & 0.631 & 0.908 & 0.909 & 0.934 & 1.000 & 1.000 \\
\hline
\end{tabular}


Table 3: Empirical Applications

\begin{tabular}{ccccccccccc}
\hline & \multicolumn{3}{c}{$t_{N L}$} & \multicolumn{3}{c}{ EG } & \multicolumn{3}{c}{ ADF } \\
\hline Series & $\hat{\theta}$ & $\mathrm{NC}$ & $\mathrm{C}$ & $\mathrm{CT}$ & $\mathrm{NC}$ & $\mathrm{C}$ & $\mathrm{CT}$ & $\mathrm{NC}$ & $\mathrm{C}$ & $\mathrm{CT}$ \\
\hline$q_{\mathrm{uk}, \mathrm{a}}$ & $0.058^{a}$ & -0.871 & $-3.778^{a}$ & $-3.658^{a}$ & $\mathrm{NA}$ & $7.234^{a}$ & $9.854^{a}$ & -0.255 & $-3.794^{a}$ & $-4.327^{a}$ \\
$q_{\mathrm{uk}}$ & $0.009^{a}$ & -1.434 & $-2.671^{b}$ & -2.576 & 1.543 & 3.227 & 3.933 & -0.385 & -2.488 & -2.753 \\
$q_{\mathrm{jp}}$ & $0.007^{a}$ & -0.630 & -2.530 & -2.807 & $\mathrm{NA}$ & 2.157 & 1.6806 & -0.457 & -2.076 & -1.810 \\
$q_{\mathrm{can}}$ & $0.004^{b}$ & -0.990 & -1.513 & -1.264 & 0.413 & 1.235 & 1.065 & -0.448 & -1.556 & -1.005 \\
$q_{\mathrm{fr}}$ & $0.010^{a}$ & -0.446 & -1.831 & -1.675 & $\mathrm{NA}$ & 2.444 & 2.540 & -0.088 & -2.014 & -2.090 \\
$b_{\mathrm{ftse}}$ & $0.0145^{a}$ & $-4.162^{a}$ & $-4.216^{a}$ & $-4.351^{a}$ & $29.393^{a}$ & $29.393^{a}$ & $33.288^{a}$ & $-7.661^{a}$ & $-7.660^{a}$ & $-8.154^{a}$ \\
$h p-y$ & $0.011^{b}$ & -0.171 & -1.770 & -1.914 & NA & 1.553 & 1.751 & -0.129 & -1.645 & -1.679 \\
$d-p$ & $0.009^{b}$ & -0.424 & -2.597 & $-3.186^{b}$ & NA & 1.234 & 3.191 & -0.044 & -1.533 & -1.340 \\
$\pi$ & $0.047^{a}$ & -0.761 & -1.136 & -1.799 & 0.389 & 1.429 & 1.334 & 0.837 & -0.031 & -1.178
\end{tabular}

Notes: NA indicates that the value is not available due to the fact that the computation of the statistic is not feasable. NC, C and CT correspond to the case of no constant, constant and constant and trend, respectively. ${ }^{a}$ and ${ }^{b}$ denote significance at 5 and 10 per cent significance level, respectively. 


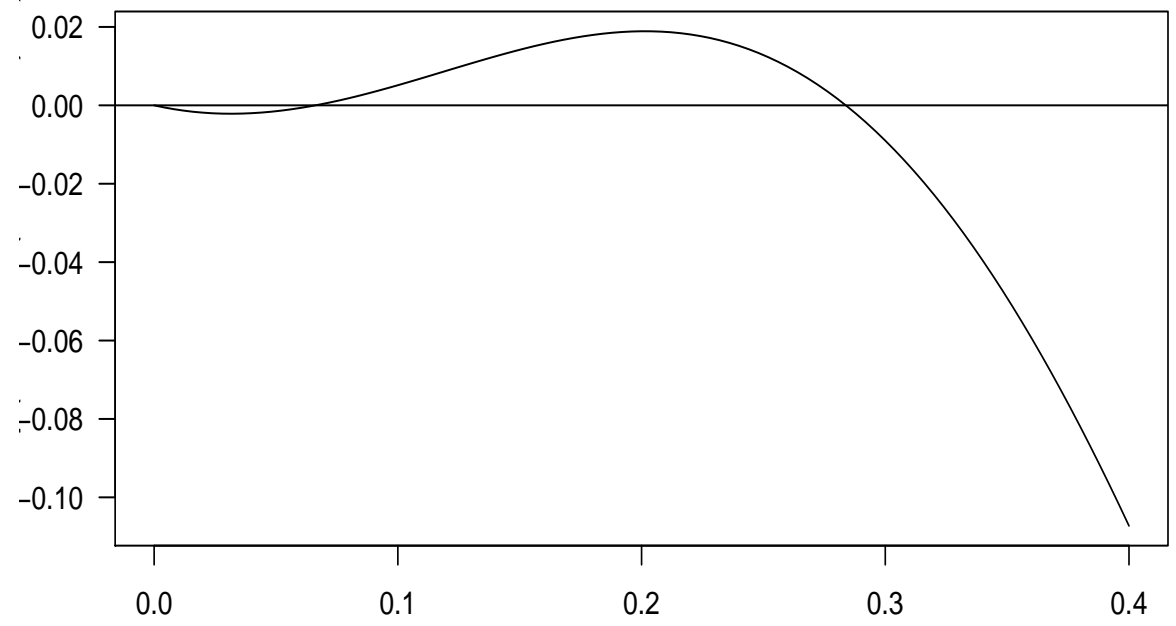

Figure 1: Equilibria of the skeleton of Model (2)

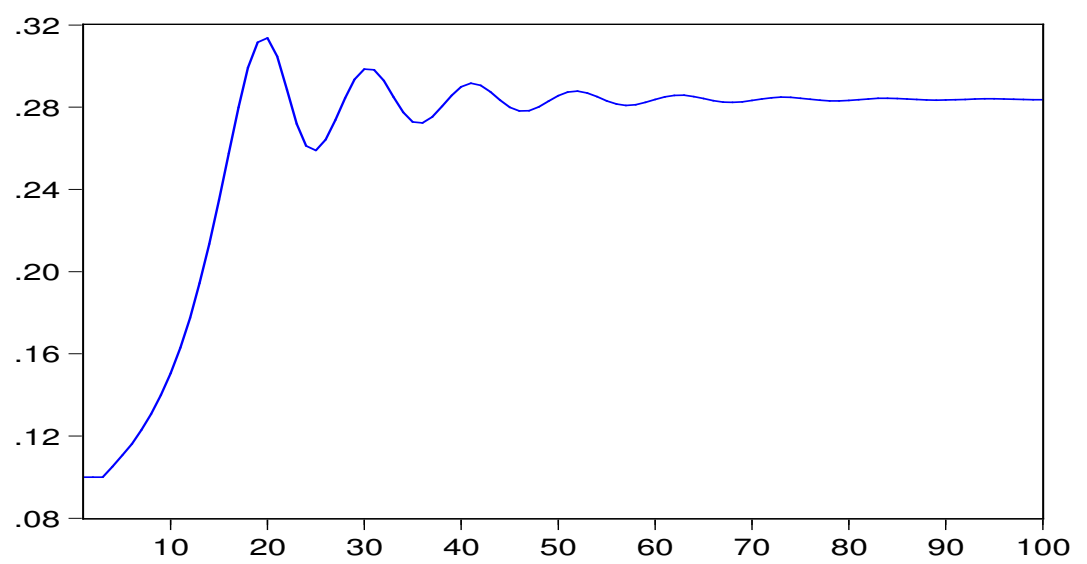

Figure 2: Realization of Model (2) with no noise and starting value of 0.1 


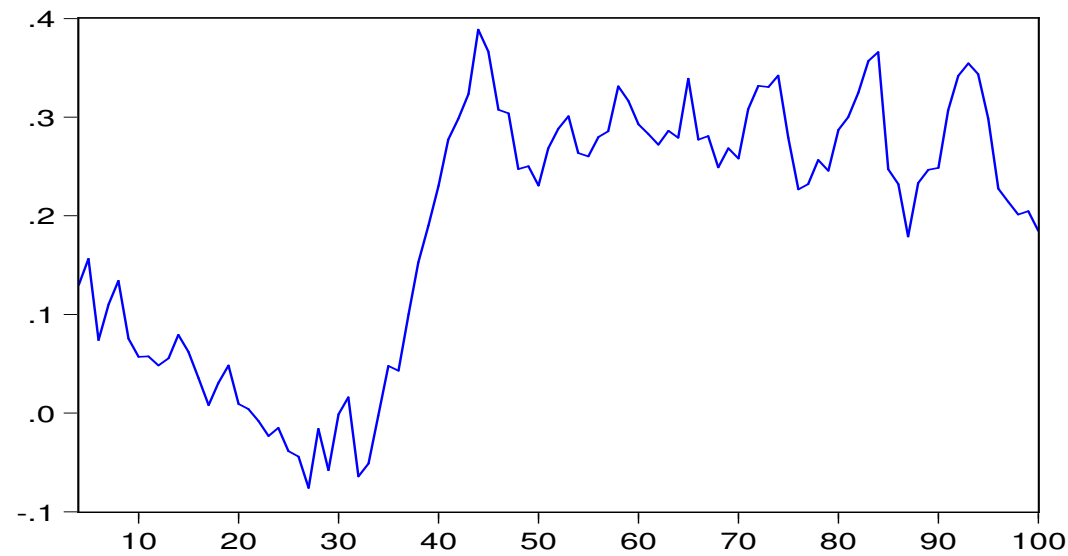

Figure 3: Realization from Model (2) with noise and starting value of 0.1

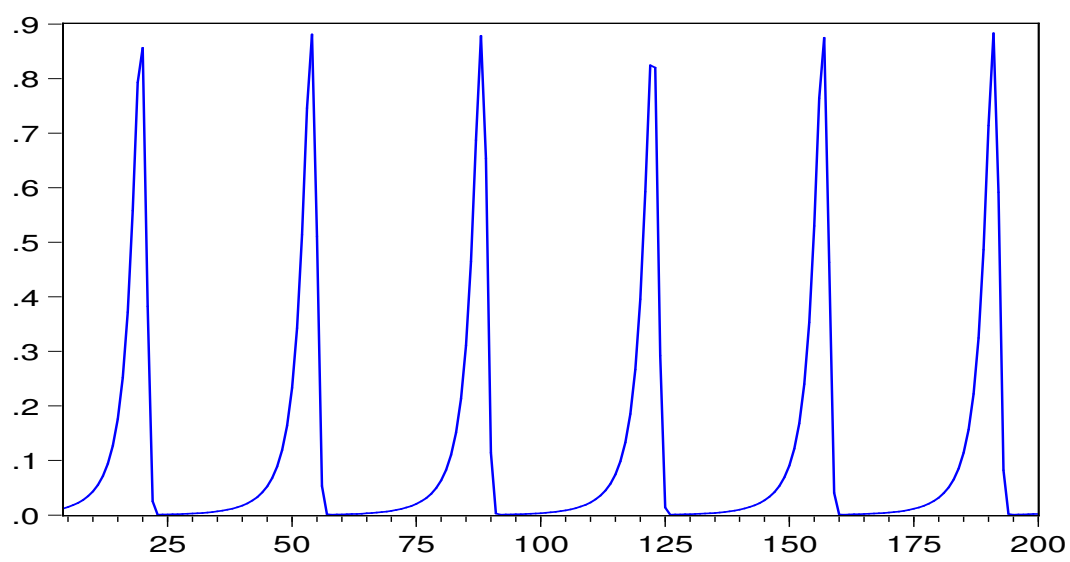

Figure 4: Realization from Model (2) with autoregressive coefficient 1.5, no noise and starting value of 0.1 


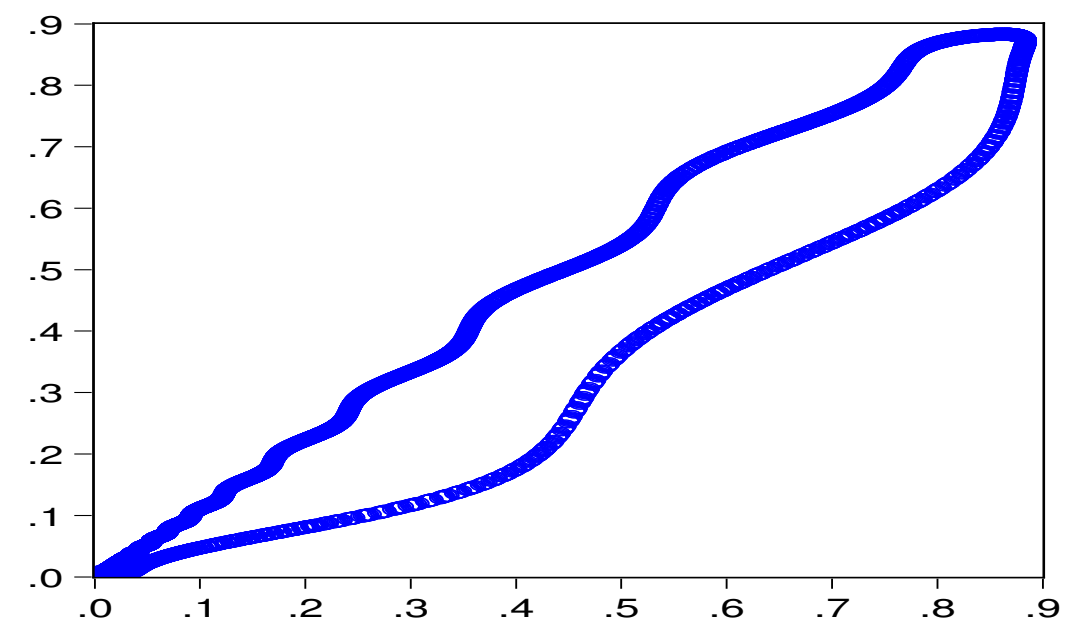

Figure 5: Scatter plot of $y_{t}$ on $y_{t-34}$ of 10,000 realizations from Model (2) with autoregressive coefficient 1.5 , no noise 

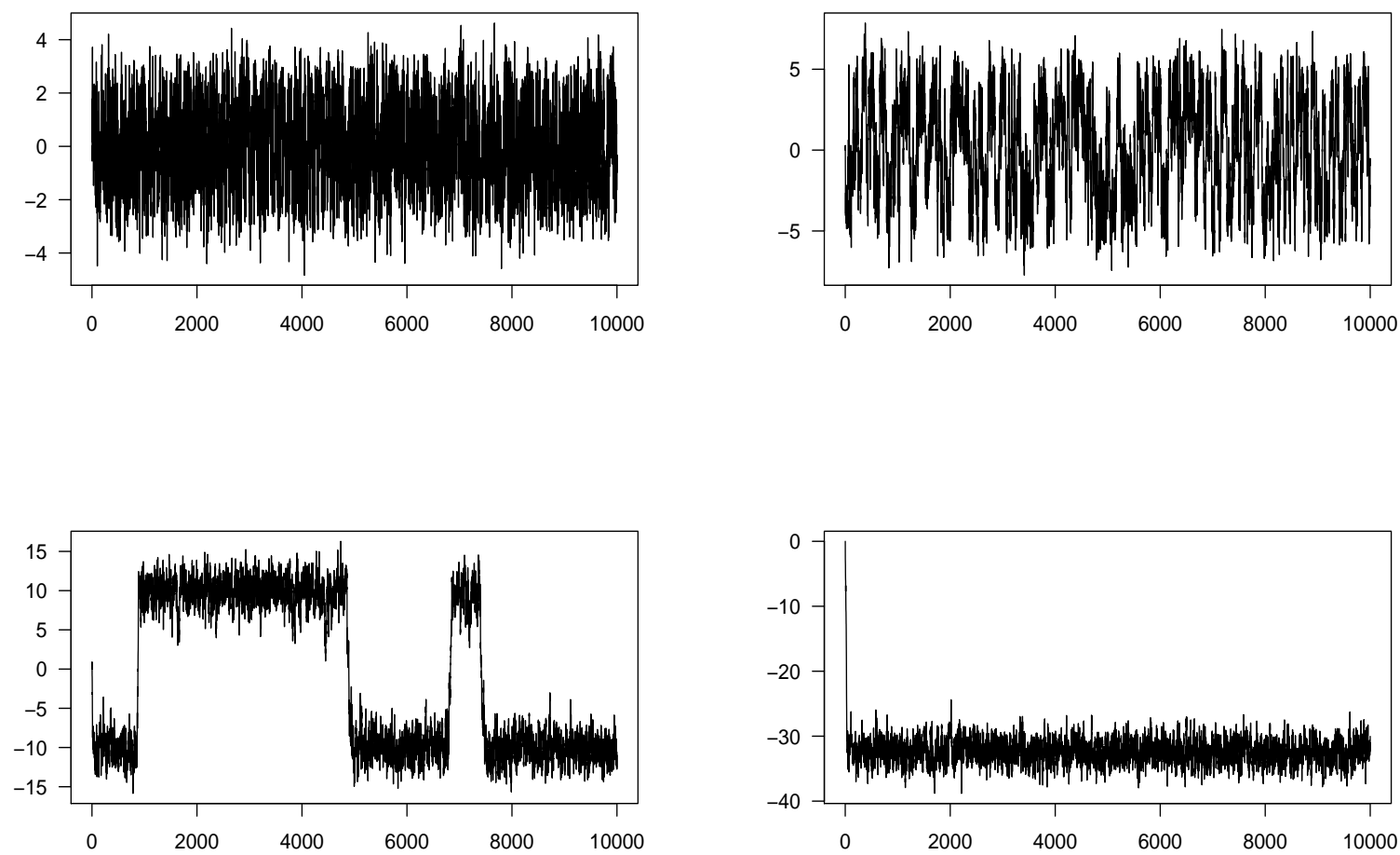

Figure 6: Four simulated ESTAR processes. The parameter values for the DGPs are $\gamma=-1$, $\phi=0.1$ and $\theta$ is set equal to 0.1 (top-left), 0.01 (top-right), 0.001 (bottom-left), and 0.0001 (bottom-right). 